\title{
"O amor fala todas as línguas: assistente social na luta contra o preconceito" - reflexões sobre a campanha do conjunto CFESS/CRESS
}

\author{
Marylucia Mesquita* \\ Maurílio Castro de Matos**
}

\begin{abstract}
Resumo: $\mathrm{O}$ artigo pretende refletir criticamente sobre a campanha nacional pela livre orientação e expressão sexual: "O amor fala todas as línguas: assistente social na luta contra o preconceito", lançada pelo Conselho Federal de Serviço Social, em conjunto com os Conselhos Regionais de Serviço Social, em 2006. Para tanto, realiza uma breve discussão sobre o necessário combate à homofobia, à lesbofobia e à transfobia como estratégia de garantia da diversidade e dos direitos humanos, para assim refletir sobre a importância do/ a assistente social participar também desse combate, tomando como referência para essa discussão os atuais preceitos éticos da profissão.

Palavras-chave: Livre orientação e expressão sexual; serviço social; combate ao preconceito.
\end{abstract}

\begin{abstract}
The paper reflects critically on national campaign for free expression and sexual orientation: "Love speaks every language: Social Work in the fight against prejudice" launched by the Federal Council of Social Service, in conjunction with the Regional Councils of Social Service in 2006. The study presents a brief discussion of the need to combat homophobia, and transphobia, lesbophobia as a strategy for ensuring diversity and human rights, in order to reflect on the importance of the / a social worker also attend the match, taking as reference this discussion of current ethical profession.

Keywords: Free expression and sexual orientation; social work; fight against prejudice.
\end{abstract}

\section{Introdução}

O Conselho Federal de Serviço Social (CFESS), em conjunto com os Conselhos Regionais de Serviço Social (CRESSs) ${ }^{1}$, lançou em 2006 uma campanha nacional pela livre orientação e expressão sexual: "O Amor fala todas as línguas: assistente social na luta contra o preconceito". Tratou-se de uma campanha que visou des-

\footnotetext{
* Assistente Social, mestre em Serviço Social (UFPE). Coordenadora do Núcleo de Formação e Pesquisa em Direitos Humanos LGBT da Prefeitura de Fortaleza e ex-conselheira do Conselho Federal de Serviço Social (CFESS). E-mail: mauriliomatos@gmail.com

** Assistente Social, doutor em Serviço Social (PUC/SP), professor adjunto da Faculdade de Serviço Social da UERJ e atual conselheiro do Conselho Federal de Serviço Social (CFESS). E-mail: marylucia@cfess.org.br

1 Passaremos a denominá-los, a partir daqui, de conjunto CFESS/CRESS.
} 


\section{heVistg a lil pgutg}

\} "O AMOR FALA TODAS AS LÍNGUAS" - MESQUITA, M. \& MATOS, M. C. \}

naturalizar e desconstruir a heterossexualidade como a única expressão socialmente legítima da sexualidade humana, uma vez que, como recurso ideológico do patriarcado, traz consequências nocivas àqueles/àquelas que (não) "ousam dizer o nome". A negação de direitos é apenas uma delas. É de domínio público que não há na sociedade nenhuma polêmica sobre a expressão pública da heterossexualidade. No entanto, o amor e o sexo entre homens e entre mulheres não só é polêmico, mas, muitas vezes, alvo de profundos preconceitos que invadem todas as dimensões da vida social, quer de forma velada ou explícita.

$\mathrm{Na}$ época do lançamento, alguns segmentos da categoria problematizaram qual a relevância e o porquê dessa campanha. As indagações giraram em torno da dúvida quanto à existência de outro tema mais importante para ser debatido. Tivemos acesso a informações, por meio de representantes dos CRESS do Rio de Janeiro, de São Paulo e do Ceará (gestões 2005/2008), sobre polêmicas nas equipes de serviço social, acerca da fixação ou não do material informativo da campanha, com a realização, inclusive, de votação entre os/as profissionais sobre a sua exposição ou não. E, ainda, que havia temas mais importantes a serem tratados, que era uma campanha inadequada e que o CFESS não tinha que se envolver com tais questões.

Este cenário nos convidou para uma reflexão ética sobre o significado da campanha. Vale realçar que essa não foi a primeira campanha do conjunto CFESS/ CRESS. Outras denúncias e outros preconceitos já foram enfrentados em outras campanhas $^{2}$. Mas, por que esta teve e permanece tendo uma reação conservadora por parte de determinados segmentos da categoria? Antes de problematizar a direção ético-política dada ao exercício profissional daquelas/daqueles assistentes sociais que compreenderam/compreendem que, por exemplo, não se deveria, no espaço sócio-ocupacional, dar caráter público ao material da campanha, consideramos necessário desvelar a questão. É esse caminho que percorreremos neste artigo.

O ponto de partida, acreditamos, é a reflexão sobre o atual projeto profissional e sua relação (ou não) com a sociabilização primária da maioria dos/as assistentes sociais e os valores morais constituídos a partir daí por estes sujeitos na vida adulta.

O projeto profissional que parte expressiva da categoria dos/as assistentes sociais vem construindo e fortalecendo, desde os idos da segunda metade da década de 1970, denominado "projeto ético-político do serviço social", se pauta em uma recusa ao histórico conservadorismo da profissão e aponta para a construção de um fazer profissional comprometido com a liberdade e a justiça social, valores centrais do atual Código de Ética, promulgado em 1993.

A liberdade é tratada na perspectiva que compreende o ser humano como capaz de liberdade e, portanto, não se insere no plano do inacessível, no idealismo.

\footnotetext{
${ }^{2}$ Ganha relevo a partir da gestão $2002 / 2005$ do CFESS a realização de campanhas nacionais com a finalidade de defesa do projeto ético-político profissional. Dessa forma, foram promovidas campanhas de enfrentamento de diferentes questões: Campanha Nacional de Combate ao Racismo (2005); assim como foram deliberadas e aprovadas, no $34^{\circ}$ Encontro Nacional CFESS/CRESS (Manaus/AM, 2005), proposições pela continuidade de campanhas nacionais de Defesa dos Direitos Humanos, priorizando o combate à discriminação e preconceitos, respeitando a diversidade e, também, o propósito de realizar uma "campanha nacional em defesa da liberdade de orientação sexual", realizada em 2006, com o lema "O Amor fala todas as Línguas: assistente social na luta contra o preconceito" (2006a). Foi promovida, ainda, a campanha "Direitos Humanos, Trabalho e Riqueza no Brasil", e a gestão atual, "Tempo de Luta e Resistência" (2011/2014), assume como desafio a continuidade de tais campanhas.
} 


\title{
hevistg em pautg
}

\} "O AMOR FALA TODAS AS LÍNGUAS" - MESQUITA, M. \& MATOS, M. C. \}

A liberdade constitui-se em realidade por meio da possibilidade que homens e muIheres têm de realizar escolhas, que, obviamente, são determinadas historicamente.

A justiça social, no código, remete para a defesa de uma socialização daquilo que é socialmente produzido, mas privadamente apropriado. Assim, o código remete à crítica ao capitalismo. Contudo, reconhece os limites da atuação profissional que, inscrita na sociabilidade capitalista, defende as políticas públicas, mas compreende que essas não irão eliminar a desigualdade social. Afinal, como nos adverte Santos, um dos nossos maiores desafios contemporâneos, em tempos de avanço do pensamento conservador, consiste em qualificar a direção de nossas lutas, pois:

\begin{abstract}
Sabemos que o campo da democracia e dos direitos é permeado por tensões/contradições em que, se por um lado, a luta pela democratização das relações so-ciais e por acesso a direitos é necessária, por outro, representa limites, na medida em que a determinação central para a garantia da igualdade e da liberdade não vem da conquista do direito, mas da transformação da sociabilidade vigente (2009, p. 106).
\end{abstract}

Em outros termos, o projeto de profissão - do qual o Código de Ética é um dos pilares - tem em seu substrato a emancipação humana como horizonte societário, uma vez que sob a sociabilidade capitalista somente é possível a emancipação política. Por isso adota princípios e valores não irracionalistas que, em condições objetivas determinadas historicamente, reconhece em homens e mulheres a condição de sujeitos responsáveis por suas escolhas, seus projetos de vida.

Embora, portanto, o código não se proponha a regular a vida privada dos/as assistentes sociais, o mesmo se choca com concepções de mundo pautadas em todos os tipos de irracionalismo que, por vezes, marcam as trajetórias de vida dos/ as profissionais. Também colide com a negação de direitos daqueles/daquelas que caminham na contramão do padrão dominante instituído e legitimado socialmente. Em miúdos: a partir da referência ao Código de Ética de 1993, podemos afirmar que não há espaço no atual projeto profissional para o exercício do preconceito e da discriminação.

Refletir sobre os preconceitos supõe, em princípio, inscrevê-los na dinâmica da vida cotidiana ${ }^{3}$ como lócus privilegiado de sua reprodução. Compreendemos que a crítica aos preconceitos e a análise cuidadosa acerca de suas múltiplas manifestações exigem considerar a cotidianidade inscrita na sociabilidade burguesa.

Cabe lembrar, conforme Heller (1989), que o preconceito é uma manifestação particular da persistência dos juízos provisórios que inicialmente construímos, mas que permanecem intocáveis mesmo quando a ciência e uma experiência cuidadosa mostram que estão errados.

Os preconceitos se sustentam e se reproduzem por meio de bases afetivas e irracionais fundadas na desinformação, na alienação, no moralismo, no conservadorismo, no conformismo e, portanto, na lógica de naturalização e banalização

\footnotetext{
${ }^{3}$ Ver Heller (1989); Barroco (2001).
} 


\section{heVistg all pgutg}

\} "O AMOR FALA TODAS AS LÍNGUAS" - MESQUITA, M. \& MATOS, M. C. \}

dos processos sociais. Partimos do entendimento de que tais determinações - o fato de estarem inscritas numa dada formação sócio-histórica - poderão explicar atitudes de discriminação, mas nunca justificá-las (MESQUITA et al., 2001).

Heller nos adverte ainda para o entendimento de que o preconceito "é sempre moralmente negativo". Isso porque "todo preconceito impede a autonomia do homem, ou seja, diminui sua liberdade relativa diante do ato de escolha, ao deformar e, consequentemente, estreitar a margem real de alternativa do indivíduo" (1989, p. 59). Nessa perspectiva, por exemplo, no que se refere à homossexualidade, há ainda um debate sobre como e por que alguns/algumas desenvolvem afetividade por pessoas do mesmo sexo/gênero e outras não. O interessante é que não há debate por que as pessoas desenvolvem orientação afetivo-sexual voltada para heterossexualidade. ${ }^{4}$ Contudo, nenhuma pesquisa séria trata a questão da homossexualidade como uma patologia ou desvio moral. Assim, o conhecimento científico já reconheceu ${ }^{5}$ a "normalidade" da questão. Mas mesmo assim sabemos o quanto a questão é negada ou é tratada de forma pejorativa. Isto é uma expressão do preconceito posto na atualidade. Na verdade, não é somente a população de lésbicas, gays, bissexuais, travestis e transexuais (LGBT) que é alvo do preconceito no Brasil. O preconceito por aqui se expressa ainda pelas opressões de raça, etnia, classe etc. A diferença é que, contra os primeiros, a agressão e o falso humor (a presença de lésbicas, gays e travestis comparece sempre estereotipada) acontecem todos os dias de maneira escancarada. Aos últimos, no Brasil, são reservadas ações preconceituosas veladas. Todos os preconceitos são anti-humanos e, portanto, devem ser combatidos.

Ser hoje um/a assistente social competente é uma tarefa desafiadora e nada fácil. Construímos um projeto de profissão que vai à contracorrente do projeto societário hegemônico. Dessa forma, os/as assistentes sociais - que se pautam no citado projeto profissional - se deparam com um caldo cultural contrário: na família, no trabalho, na sociedade... A tarefa dos/as profissionais descontentes é árdua, mas ao mesmo tempo é possível e necessária quando acreditamos naquilo que propomos e fazemos. Com capacidade intelectual e permanente leitura da realidade, numa perspectiva de totalidade, podemos construir pequenos inícios de caminhadas libertárias. Mas, precisamos acreditar que "apesar de você, amanhã pode ser outro dia" ${ }^{\prime}$ ! Para isso não basta aderir aos princípios do projeto, é necessário internalizálos.

E, neste sentido, é fundamental o entendimento de que não nascemos assistentes sociais. Nos tornamos assistentes sociais, e

\footnotetext{
${ }^{4} \mathrm{O}$ não questionamento sobre o porquê da heterossexualidade revela como ela se impõe, de forma naturalizada, como única possibilidade da sexualidade humana, impondo às demais expressões - homossexualidade e bissexualidade - o lugar do ostracismo social.

${ }_{5}^{5}$ Apesar de tardio em termos das consequências para milhares de pessoas com orientação afetivo-sexual voltada para homossexualidade, em 1985, o Conselho Federal de Medicina (CFM), no Brasil, retirou a homossexualidade do catálogo das doenças e a Organização Mundial de Saúde (OMS) fez o mesmo em 1990.

${ }^{6}$ Referência à canção de Chico Buarque de Hollanda, "Apesar de você", lançada como disco compacto em 1970, mas proibida pela censura no país no período da ditadura militar, só foi gravada novamente em 1978. Informações disponíveis, por exemplo, em < http://www.chicobuarque.com.br/discos/mestre.asp?pg=chico_78. $\mathrm{htm}>$. Acesso em 1 março de 2012].
} 


\section{hevigtg ant paltg}

\} "O AMOR FALA TODAS AS LÍNGUAS" - MESQUITA, M. \& MATOS, M. C. \}

este movimento de tornar-se é histórico, é diverso na história de cada um/uma de nós. Temos que considerar aqui a necessária temporalidade para gestar seja o/a profissional assistente social em sua dimensão individual, seja o coletivo da categoria profissional. Do ponto de vista da formação individual do/a profissional, o processo tem início no curso de graduação em Serviço Social, mas esse tempo se amplia por meio da participação política dos/as estudantes e posteriormente nas inserções em nível de pós-graduação, nas experiências profissionais cotidianas e na inserção em espaços de representação e organização política. Não podemos esquecer que a maioria dos/as assistentes sociais, ao entrar na universidade, possuía projetos voltados para as necessidades do 'eu', com aspirações e buscas ensimesmadas na própria singularidade (SANTOS, 2010, p. 704).

A Campanha "O Amor fala todas as línguas" foi e permanece sendo, ${ }^{7}$ portanto, um convite à categoria, em particular, e à sociedade em geral, para reconhecer a diversidade humana e revisitar em que medida superamos "as necessidades do eu" e acolhemos as necessidades do/a outro/a como tão legítimas quanto as nossas. Afinal, não é demais lembrar a assertiva do velho Marx, em 1875, na Crítica ao Programa de Gotha "de cada qual, segundo sua capacidade; a cada qual segundo suas necessidades".

\section{Por que o amor que não afirma o padrão dominante de sexualidade causa tanto incômodo?}

Se tudo pode acontecer / se pode acontecer / qualquer coisa / um deserto florescer / uma nuvem cheia não chover. Pode alguém aparecer / e acontecer de ser você / um cometa vir ao chão / um relâmpago na escuridão. E a gente caminhando / de mão dada / de qualquer maneira / eu quero que esse momento / dure a vida inteira / e além da vida / ainda de manhã / no outro dia / se for eu e você / se assim acontecer. Arnaldo Antunes, Paulo Tatit, Alice Ruiz e João Bandeira.

A canção acima, cantada em vozes contemporâneas da música popular brasileira, como Adriana Calcanhotto e Arnaldo Antunes, trata de um assunto clássico, presente não somente na música, mas em todas as manifestações artísticas: o amor. Em diferentes momentos da história temos registro da exaltação ao amor, cujo desejo é orientado para a heterossexualidade. No entanto, em que pese o heterossexismo ao longo da história, amar o/a outro/a e desejar ser amado/a é parte essencial da vida. Afinal, não é novidade a experiência de quando uma pessoa se sente extremamente encantada, literalmente apaixonada por outra, as suas atividades do cotidiano são suspensas. Encantar-se, afetiva e sexualmente, pelo/a outro/a promove

\footnotetext{
7 Compreendemos que as campanhas exigem uma temporalidade histórica: começo, meio e fim. No entanto, como geralmente tratam de questões não superadas na vida social, necessitam estar presentes como propostas ou ação permanente. E no âmbito do conjunto CFESS/CRESS isso se observa quando nos encontros nacionais, mesmo tendo sido encerradas as campanhas, inúmeras propostas que contribuem para pautar e consolidar os chamados "temas marginais", a exemplo do racismo e da homofobia, permanecem em nossa agenda política.
} 


\section{heVistg all pgutg}

\} "O AMOR FALA TODAS AS LÍNGUAS" - MESQUITA, M. \& MATOS, M. C. \}

um conjunto de transformações subjetivas. A fase da paixão "retira a pessoa do ar" (como comumente se diz), porém, mais do que isso, repõe para o indivíduo, por meio da suspensão de suas atividades rotineiramente realizadas no cotidiano, possibilidades de articulação do seu ser singular com a consciência humano genérica.

Obviamente, conhecemos exemplos de pessoas que viveram sem ter um companheiro, companheira, namorado, namorada, marido e esposa. Não cabem aqui reflexões sobre os porquês. Não falaremos sobre sublimações ou caminhos parecidos. Contudo, certamente, a necessidade de amar e ser amado/a é de muito mais pessoas.

Pouco explicado é o fato de por que uns são intensamente interessantes para outros e para outros tantos não. Uns se sentem atraídos por " $A$ ", mas não se sentem atraídos por "B". Sentir desejo não se trata de um ato planejado e intencional. Sente-se o desejo e "escolhe-se" vivê-lo ou não.

As perguntas que se nos impõem são: por que algo tão ontológico aos indivíduos - ou seja, amar e ser amado/a - pode incomodar tanto, como é o caso das relações afetivas e sexuais entre pessoas do mesmo sexo/gênero? Se sexo e amor só interessam para aqueles que estão diretamente envolvidos, por que a vigilância atroz do preconceito contra a população LGBT? A esse respeito, é oportuna a reflexão do CFESS Manifesta ${ }^{8}$ alusivo ao Dia Nacional da Visibilidade Lésbica:

Por que a vivência do amor entre mulheres, [entre homens], entre 'iguais', provocou ao longo da história, e, ainda, provoca, tanta hostilidade, a ponto de gerar as mais diversas e virulentas reações: rejeição familiar, repulsa social, discriminação no trabalho e violência psicológica e física? Por que esta forma de amor incomoda de tal forma que suas vivência e expressão podem, em algumas sociedades, ser punidas com prisão, perseguições, tortura e até morte? Por que as democracias modernas, mesmo após o reconhecimento e a conquista de diferentes tipos de direitos, seguem negando e interditando a homossexualidade/ lesbianidade e a bissexualidade como expressões da sexualidade humana? (CFESS, 2010b). ${ }^{9}$

Amar é uma necessidade do gênero humano e sendo necessidade é um direito. Direito este colocado na vida privada, mas também na vida pública dos sujeitos. Ora, como qualquer experiência humana, a sexualidade, como uma dimensão da individualidade humana, é resultante de um complexo articulado de processos sociais, culturais, políticos e econômicos e estes são, por consequência, historicamente determinados.

\footnotetext{
${ }^{8}$ CFESS Manifesta é um documento informativo com posicionamento político do CFESS sobre alguma situação da conjuntura. É divulgado na página do CFESS e pelas redes sociais e também é impresso em determinadas situações. Todas as edições encontram-se disponíveis no sítio do CFESS. Ao término das gestões 2005-2008 e 2008-2011 todas as edições do CFESS Manifesta foram coligidas em livros, também disponíveis na internet. Com relação ao tema, para consulta ver, respectivamente: CFESS, 2008 e 2011 b.

${ }^{9}$ Todo CFESS Manifesta é escrito por conselheiros/as das gestões do CFESS ou convidados/as e aprovado pela diretoria do CFESS. Esse foi escrito pelas conselheiras da gestão 2008-2011, Ivanete Boschetti e Marylucia Mesquita.
} 


\section{hevistg all pautg}

\} "O AMOR FALA TODAS AS LÍNGUAS" - MESQUITA, M. \& MATOS, M. C. \}

Ao refletir sobre a heterossexualidade obrigatória e sua nefasta consequência - a lesbofobia/homofobia/transfobia -, Mesquita tem desenvolvido a tese de que a prática afetivo-sexual, como construção sócio-histórica, possui duas dimensões que se determinam reciprocamente e não podem ser compreendidas de maneira dissociada. Trata-se das dimensões privada e pública ou, de outro modo, pessoal e coletiva. A esse respeito, a autora acrescenta:

As práticas afetivo-sexuais em si possuem uma dimensão, essencialmente, privada. Cada um/a na sua singularidade é quem vive, sente e deseja o seu 'objeto de desejo' e escolhe como vai expressar e responder a suas fantasias e necessidades sexuais. E são estes indivíduos concretos, historicamente determinados que experienciam os (dis)sabores da sua prática afetivo-sexual. Nesse sentido, ao se restringir a sexualidade ao âmbito da 'ética privada', o debate se põe de forma insuficiente, superficial, posto que a responsabilidade passa a ser individualizada, contribuindo assim para inúmeras formas de violência, dominação e opressão (2001, p. 3).

A prática afetivo-sexual per si supõe também, no entanto, a garantia de uma dimensão pública, coletiva, com bases históricas. No que diz respeito ao ser humano, demanda garantia de efetivação - sem interdição - de suas múltiplas expressões eróticas, quer sejam no âmbito da homossexualidade, heterossexualidade ou bissexualidade. Também na esfera pública, a sexualidade é uma dimensão fundamental da nossa existência. Logo, não deve permanecer no ostracismo social (MESQUITA, 2001). Afinal, a sexualidade é parte integral constitutiva da individualidade de todo ser humano e seu desenvolvimento total depende da satisfação de necessidades humanas básicas, tais como: desejo de contato, intimidade, expressão emocional, prazer, carinho e amor. Nessa perspectiva, a sexualidade é construída por meio da interação entre o indivíduo e as estruturas sociais. O pleno desenvolvimento da sexualidade é essencial para o bem-estar individual, interpessoal e social (MESQUITA, 2001).

Mais ainda, viver a sexualidade assume caráter público no sentido de que não há justificativas, senão de cunho moralista e conservador, que incorporem legitimidade quando cerceiam direitos considerados fundamentais: os direitos sexuais. Cabe-nos indagar: o que leva pessoas e instituições a se reivindicarem autorizadas e legítimas a determinar como os indivíduos devem relacionar-se afetiva e sexualmente? Que elementos justificam que indivíduos e instituições coloquem em xeque a competência e o compromisso profissionais de homens e mulheres que possuem orientação sexual diferente do padrão dominante de sexualidade? Em que medida efetiva-se a laicidade do Estado brasileiro em relação ao tema?

Vivemos, no entanto, em uma sociabilidade em que o padrão de sexualidade dominante é o da heterossexualidade compulsória, que se configura como um sistema de dominação instituído, legitimado social e historicamente como modelo, norma, dogma, prática natural - inquestionável (MESQUITA, 2001). Dessa forma, 


\section{heVistg all pgutg}

\} "O AMOR FALA TODAS AS LÍNGUAS" - MESQUITA, M. \& MATOS, M. C. \}

na experiência da heterossexualidade curiosamente não há dicotomia entre a dimensão pública e a dimensão privada. Estas duas dimensões da sexualidade são não apenas reconhecidas, mas legitimadas socialmente por meio da família, da mídia, das legislações, do acesso às políticas sociais etc. Para a experiência homoafetiva, geralmente, as alternativas estão predeterminadas: o silêncio, o ocultamento, a negação, a "vida dupla". Ou seja, a partilha das "dores e delícias" da experiência do amor entre mulheres e entre homens não é a realidade da maioria da população LGBT, tanto na família quanto no trabalho e em outros espaços de sociabilidade impõe-se a invisibilidade ou, no máximo, a "identidade discreta", nos termos do autor argentino Mario Pecheny (2004).

Só por aqui podemos perceber o quanto antiemancipatório é dizer para o/a outro/a como ele deve ser, sentir ou agir, perante uma necessidade que, quando respondida, não afeta na sociabilidade e nos direitos dos outros. Somente irá afetar se tivermos partindo de um pressuposto moralista, conservador e autoritário em que se nega a alteridade e a capacidade de reconhecer os outros como sujeitos éticos capazes de liberdade.

\section{Um balanço da campanha}

A categoria dos/as assistentes sociais, como de outras profissões, não está imune ao caldo preconceituoso largamente existente no Brasil. Afinal, a título de ilustração, todo sábado à noite assistentes sociais e não assistentes sociais, se quiserem, podem assistir a inúmeras versões do preconceito contra lésbicas, gays e travestis veiculados no programa "Zorra Total". Por isso, até o momento, tematizamos sobre os preconceitos resultantes do padrão dominante de sexualidade. Contudo, se a categoria profissional também é sociabilizada neste contexto heterossexista e, portanto, marcado pela homofobia/lesbofobia/transfobia social e institucional, isso não pode ser entendido como uma desculpa, uma justificativa para a prática da discriminação, sobretudo quando nos propomos fortalecer e consolidar a cada dia nosso Projeto Ético-Político do Serviço Social brasileiro. Exatamente por isso, uma campanha dessa natureza se torna ainda mais importante. Não é demais ressaltar que raras são as profissões que ousaram construir um projeto profissional como o nosso: esse projeto é em todos os sentidos contra-hegemônico. Como o projeto profissional é processo, essa contra-hegemonia necessita ser forjada cotidiana e permanentemente. Como nos referimos anteriormente, o conjunto CFESS/CRESS já tomou outras iniciativas de combate à discriminação ou de denúncia dos efeitos predatórios do neoliberalismo. No entanto, como atentou Lúcia Barroco, em depoimento disponível no CFESS Manifesta, "essa campanha é diferente". E argumentou que é diferente

porque - de forma diversa de outras, que foram legitimadas naturalmente pela categoria, essa toca em uma questão que é tabu para grande parte da sociedade: o amor entre pessoas do mesmo sexo (...) não podemos tratar nossos usuários de forma preconceituosa e discriminatória, negando, com isso, a ética profissional e o respeito à liberdade do outro de ser diferente, de 


\section{hevigtg ant paUtg}

\} "O AMOR FALA TODAS AS LÍNGUAS" - MESQUITA, M. \& MATOS, M. C. \}

fazer escolhas e ter direitos. O principal avanço de nosso projeto ético-político está materializado na busca de ruptura com o conservadorismo profissional: essa campanha e a nossa contribuição, realizando-a em nosso cotidiano é mais uma etapa nessa consolidação $\left(2007\right.$, p. 6) ${ }^{10}$.

Compreendemos que a campanha foi inovadora porque marcou a defesa e ampliação de direitos de uma população historicamente aviltada nas suas condições de existência, a população LGBT. E mais, o Conjunto CFESS/CRESS - ao articular com movimentos sociais que denunciam opressões particulares - permanece, apesar dos tempos sombrios, com "atitude crítica para avançar na luta", inscrevendo na história o compromisso do Serviço Social brasileiro com a diversidade humana como valor emancipatório.

A campanha foi/é uma iniciativa inovadora porque se constituiu em uma ação política e pedagógica de desconstrução da heterossexualidade obrigatória e heteronormatividade, além de marcar posição em defesa da garantia e ampliação de direitos da população LGBT. Tratou-se de um convite para uma mudança de postura e de atitude, de revisitação de preconceitos, na medida em que a campanha visava à sensibilização da categoria para a garantia de acesso - dos sujeitos que vivenciam a opressão por orientação sexual não heterossexual e por identidade de gênero - aos serviços sociais (MESQUITA, 2001).

Em 2006, ano de lançamento da campanha, durante o 35ํㅡㄹ Encontro Nacional CFESS/CRESS em Vitória/ES, foram realizados debates sobre o tema por diversos Conselhos Regionais de Serviço Social. E nos encontros descentralizados e locais dos CRESS foram feitos lançamentos da campanha.

Uma das ações mais relevantes da campanha foi a aprovação da Resolução 489/2006, que "estabelece normas vedando condutas discriminatórias ou preconceituosas, por orientação e expressão sexual por pessoas do mesmo sexo, no exercício profissional do/da assistente social" (CFESS, 2006b).

A campanha demonstrou sintonia com movimentos sociais e grupos historicamente estigmatizados e, especialmente, o debate alcançou a direção política da categoria e uma parte significativa dela. O posicionamento do conjunto CFESS/ CRESS, pela defesa da livre expressão da orientação sexual, não se encerrou com a campanha em 2006. Ao contrário, pois, desde então - de forma incisiva, cabe lembrar, já que a defesa desses direitos está inscrita explicitamente desde 1993 como um dos princípios do Código de Ética - tem sido pauta das comissões de ética dos CRESS e tema de articulação com movimentos sociais que compartilham desse posicionamento e bandeira de luta permanente do conjunto.

Na I Conferencia Nacional GLBT ${ }^{11}$ em 2008, o CFESS participou e publicizou seu posicionamento - e desde então vem participando das conferências e atividades

\footnotetext{
${ }^{10}$ CFESS Manifesta que tratou do lançamento e das várias ações da campanha realizada em vários estados do Brasil. ${ }^{11}$ Até esta conferência se utilizava GLBT. Por reivindicação do movimento de mulheres lésbicas foi aprovada a alteração da sigla para LGBT como uma forma de dar visibilidade à opressão vivenciada por serem mulheres e lésbicas. A título de ilustração vale ressaltar que, infelizmente, muitas mulheres lésbicas — sobretudo de periferia, ao negar o patriarcado e a heterossexualidade obrigatória, publicizando a sua orientação sexual — são vítimas do chamado "estupro corretivo" por ex-companheiros, ex-namorados e homens em geral.
} 


\section{heVistg all pgutg}

\} "O AMOR FALA TODAS AS LÍNGUAS" - MESQUITA, M. \& MATOS, M. C. \}

contra a homofobia/lesbofobia/transfobia, bem como tem dado visibilidade pública por meio do CFESS Manifesta nesses eventos ou em datas importantes como, por exemplo, o Dia Nacional da Visibilidade Lésbica - do qual podemos ver a sintonia com os movimentos sociais da área, uma vez que apresenta os seguintes compromissos:

- Crítica à sociabilidade do capital e sua apropriação mercantil de todas as dimensões da vida social e em particular das demandas no campo da diversidade sexual;

- Intervenção nos espaços institucionais e na mídia contra a exploração do trabalho e todas as formas de opressão, como uma política firme e crítica contra a reprodução da desigualdade social; da regressão dos direitos e de políticas sociais focalistas e fragmentadas;

- Defesa intransigente da igualdade, da liberdade e dos direitos; recusa do arbítrio e do autoritarismo; empenho na eliminação de todas as formas de preconceito e violência expressas na reprodução da homofobia/lesbofobia/ transfobia, do racismo, do machismo e do sexismo;

- Luta permanente para que as políticas sociais contemplem a perspectiva de gênero, raça/etnia, orientação sexual e identidade de gênero em sintonia com a agenda política feminista e com as lutas históricas do Serviço Social no campo da Seguridade Social.

- Valorização da diversidade humana com reconhecimento da livre orientação e expressão sexual e defesa dos direitos GLBTT no âmbito da política de Saúde; da política de Assistência Social, da Previdência Social; da política de Educação; da política de Trabalho, geração de emprego e renda, da política de Segurança Pública e no acesso à cidade (moradia, espaços de lazer como restaurantes e bares etc.);

- Atendimento por assistente social à população GLBTT sem discriminar, considerando o Código de Ética Profissional e a Resolução CFESS n. 489/ 2006;

- Articulação com entidades e movimentos sociais que defendem a livre orientação e expressão sexual para aprovação do PLC 122/2006, que trata da criminalização da homofobia, do PL 81/2007, que institui o '17 de maio' como Dia Nacional de Combate à Homofobia e do PL 2000/2007, que institui o "29 de agosto" como Dia Nacional da Visibilidade Lésbica (CFESS, 2008) ${ }^{12}$.

Em 2010, no Dia Internacional do Orgulho Gay, o CFESS divulgou mais um CFESS Manifesta e nesse estão listadas as atividades desenvolvidas pelo Conjunto CFESS/CRESS na luta contra o preconceito e a homofobia/lesbofobia/transfobia:

- o lançamento da Campanha Nacional pela liberdade de orientação e expressão sexual 'O Amor fala todas as línguas: assistente social na luta contra o preconceito';

\footnotetext{
${ }^{12}$ Esse CFESS Manifesta foi escrito pelas conselheiras da gestão 2008-2011: Silvana Mara de Morais dos Santos, Marylucia Mesquita e Ivanete Boschetti.
} 


\section{hevigtg ant paltg}

\} "O AMOR FALA TODAS AS LÍNGUAS" - MESQUITA, M. \& MATOS, M. C. \}

- a publicação da Resolução CFESS 489/2006, um desdobramento da Campanha, e que regulamenta um dos princípios do Código de Ética Profissional; - o apoio à aprovação do PLC 122/2006, que propõe a criminalização da homofobia;

- a participação na campanha articulada pelo Grupo Arco-íris pela aprovação do PLC 122;

- a manifestação pública ${ }^{13}$ de seu repúdio à Faculdade de Minas (Faminas) de Muriaé, que impediu a divulgação do cartaz da 7ạ Semana Acadêmica de Serviço Social, que trazia a arte da capa da Agenda do/a Assistente Social (CFESS, 2009), que, entre outros sujeitos, explicitava um casal de lésbicas se beijando. Por este motivo, a coordenadora do curso, à época, foi demitida do Curso de Serviço Social, a assistente social Viviane Souza Pereira, que organizou o evento e defendeu a manutenção da imagem, em consonância ao Código de Ética Profissional do/a Assistente Social;

- a participação, em 2008, da 1aㅡ Conferência Nacional GLBT;

- a participação, em 2010, da 1a Marcha Nacional contra a Homofobia, que teve representantes de todas as regiões do país;

- a participação em diferentes espaços de controle democrático e defesa da liberdade de orientação e expressão sexual e identidade de gênero;

- a luta pelo direito à cidade sem homofobia/lesbofobia/transfobia;

- a articulação da luta pela diversidade humana à luta anticapitalista;

- a compreensão de que o dia 28 de junho é dia de luta em defesa dos direitos humanos LGBT. É dia de orgulho porque o que ameaça e desumaniza é o preconceito e a discriminação (homofobia/lesbofobia/transfobia). A liberdade de orientação e expressão sexual e a identidade de gênero são dimensões da diversidade humana e por isso integram a agenda de luta do Serviço Social brasileiro (CFESS, 2010a). ${ }^{14}$

Portanto, conforme afirma o relatório final da gestão 2008-2011:

Os posicionamentos do CFESS foram também amplamente divulgados durante as Conferências Nacionais de Direitos Humanos e Conferência Nacional LGBT, com participação de conselheiras nos anos em que ocorreram e distribuição de material como cartazes, adesivos, e fixação de faixas alusivas às temáticas.

Os posicionamentos públicos e ações em defesa dos direitos humanos levaram o CFESS a receber, em 2010, o prêmio de Direitos Humanos e Cidadania LGBT, juntamente com o CRESSMG, em reconhecimento à luta contra a homofobia. O prêmio foi entregue pelo Centro de Luta pela Livre Orientação Sexual de Minas Gerais (CELLOS-MG) (CFESS, 2011a, p. 19).

\footnotetext{
${ }^{14}$ Esse CFESS Manifesta foi escrito pelas conselheiras da gestão 2008-2011: Silvana Mara de Morais dos Santos, Marylucia Mesquita e Kátia Madeira.
} 


\section{heVistg all pgutg}

\} "O AMOR FALA TODAS AS LÍNGUAS" - MESQUITA, M. \& MATOS, M. C. \}

As ações e o posicionamento da gestão do CFESS de 2008-2011 - tanto como os da gestão de 2005-2008, que criou a campanha - possuem total sintonia com a plataforma da atual gestão do CFESS (2011-2014), conforme alguns extratos que destacamos abaixo:

O CFESS participou da segunda marcha nacional contra a homofobia, realizada no mês de maio de 2011 em Brasília, quando o CFESS, por meio da atual presidente Sâmya Ramos, disse do alto do carro de som:

Quero dizer aos/às companheiros aqui presentes que os/as assistentes sociais estão nessa luta por uma sociedade livre de qualquer discriminação ou desrespeito aos direitos de gays, lésbicas, travestis, bissexuais e transexuais. Como diz a nossa campanha lançada em 2006, o amor fala todas as línguas.

Recentemente houve a publicação da Resolução CFESS n. 615/2011 que permite a assistentes sociais travestis e transexuais a utilização do nome social na carteira de identidade e na cédula de identidade profissional. Compreendemos que esta resolução, além de contribuir para resguardar direitos, poderá criar terreno fértil para a ampliação do debate, no âmbito da categoria, em torno da desconstrução do entendimento da identidade de gênero ${ }^{15}$ numa perspectiva binária (ou é feminino ou é masculino) (CFESS, 2011d).

Por fim, queremos sinalizar as deliberações do último Encontro Nacional do Conjunto CFESS/CRESS, realizado em 2011 na cidade de Brasília, no qual foram aprovadas as seguintes ações:

- Dar continuidade ao debate contemporâneo acerca do uso do nome social nos espaços públicos e privados (conforme Carta de Direitos dos Usuários do SUS) e no acesso às políticas públicas para a população LGBT, considerando o respeito à diversidade de orientação sexual e a identidade de gênero, elaborando instrumentais que garantam a ampla divulgação da Resolução CFESS n. 615/2011.

- Reproduzir o cartaz de Campanha 'O amor fala todas as línguas' para a II Conferência Nacional LGBT.

- Realizar o processo de discussão e publicização do Plano Nacional Cidadania e Direitos Humanos - LGBT nos espaços de debate do conjunto CFESS/CRESS e apoio à discussão em outros espaços públicos.

- Colaborar com o Movimento LGBT e demais movimentos para a criação de frentes.

- Dar continuidade às atividades desenvolvidas a partir da Campanha pela Livre Orientação e Expressão Sexual, bem como o combate ao racismo, como

\footnotetext{
${ }^{15}$ Compartilhamos do entendimento de identidade de gênero como a "experiência interna e individual do gênero de cada pessoa, que pode ou não corresponder ao sexo atribuído no nascimento, incluindo o senso pessoal do corpo (que pode envolver, por livre escolha, modificação da aparência ou função corporal por meios médicos, cirúrgicos ou outros) e outras expressões de gênero, inclusive vestimenta, modo de falar e maneirismos" (PRINCÍPIOS DE YOGYAKARTA, 2006).
} 


\section{hevistg all pautg}

\} "O AMOR FALA TODAS AS LÍNGUAS" - MESQUITA, M. \& MATOS, M. C. \}

forma de garantir o avanço junto à categoria, dado a importância do debate (CFESS, 2011c).

Além das ações mencionadas, vale destacar o apoio e o reconhecimento que o CFESS teve pela relevância da campanha por parte do movimento LGBT brasileiro, merecendo particular destaque ao Instituto em Defesa da Diversidade AfetivoSexual (DIVAS) que foi parceiro desde a elaboração do projeto da campanha junto à CEDH/CFESS, bem como da Liga Brasileira de Lésbicas (LBL) e da Associação Brasileira de Lésbicas, Gays, Bissexuais, Travestis e Transexuais (ABGLT), que foram organizações colaboradoras e que contribuíram na disseminação da campanha junto aos movimentos LGBT, feminista e outras entidades, além da participação, em alguns momentos de debate e do próprio lançamento. Merece relevo também o reconhecimento que o CFESS recebeu do grupo CELLOS/MG, que concedeu o VI Prêmio de Direitos Humanos e Cidadania de Belo Horizonte, em 22/07/2011, intitulado "Nosso VOTO quer RESPEITO, nossa LUTA é por DIREITOS".

Assim, podemos afirmar que a campanha continua em ação, em movimento com desdobramentos de várias atividades por parte do Conselho Federal e Conselhos Regionais de Serviço Social. Contudo, são inúmeros os desafios e inquietações. Destacamos alguns levantados por Mesquita (2009), exatamente na mesa que tratou do lançamento da campanha, no 35ํㅡㄹ Encontro Nacional do Conjunto CFESS/CRESS em 2006:

Enfim, a pergunta que se apresenta é: quais são os desafios colocados para o Serviço Social em termos das demandas e necessidades da população LGBT? É importante identificar como estamos incorporando essa discussão acerca da liberdade de orientação e expressão sexual e identidade de gênero no processo de formação profissional, ou seja, a livre orientação sexual e a livre identidade de gênero são tematizadas e problematizadas no curso? Como a disciplina de Política Social aborda esse debate? Além disso, algumas disciplinas não devem deixar escapar esse debate: Ética Profissional em Serviço Social; Movimentos Sociais e as [disciplinas] opcionais como: Gênero e Serviço Social; Família e Serviço Social, dentre outras. (MESQUITA, 2009, p. 127).

E, como inquietações, apontarmos ainda: (1) como a liberdade de orientação sexual está sendo trabalhada no nosso cotidiano profissional? (2) Em nosso exercício profissional, lésbicas, gays, travestis e transexuais estão sendo reconhecidos como usuários dos serviços sociais? (3) As reivindicações do movimento LGBT integram a agenda política do Serviço Social? (4) Em que medida, nós, assistentes sociais, contribuímos para reforçar ou superar uma "identidade discreta"/"identidade aprisionada" dos usuários LGBT's? (5) Contribuímos para que possam exercer autonomia, autodeterminação e liberdade ou referendamos a homofobia/lesbofobia/transfobia institucional arraigada na maioria das instituições em que atuamos? (6) Garantimos 


\section{heVistg all pgutg}

\} "O AMOR FALA TODAS AS LÍNGUAS" - MESQUITA, M. \& MATOS, M. C. \}

a socialização da informação, bem como o acesso aos benefícios, serviços e políticas sociais a esses sujeitos? (7) Quais as mediações necessárias para articular as demandas particulares a um projeto societário radicalmente crítico à sociabilidade do capitalismo patriarcal, que produz desigualdade e opressão? (MESQUITA, 2009, p.127).

Enfim, essas questões devem ser permanentemente problematizadas entre os/as assistentes sociais. Para o enfrentamento dessa questão, entendemos que a universidade e as entidades da categoria dos/as assistentes sociais podem e devem contribuir e se posicionar criticamente. A campanha "O amor fala todas as línguas: assistente social na luta contra o preconceito" foi (e é) a contribuição dos Conselhos Federal e Regionais de Serviço Social, para a construção de uma sociabilidade sem homofobia, lesbofobia e transfobia, portanto, com respeito à diversidade humana e no horizonte de uma sociabilidade anticapitalista, verdadeiramente emancipada, com igualdade substantiva, em que as pessoas possam viver livremente os seus afetos, os seus desejos e seus projetos de vida sem interdições moralistas. 


\section{Referências bibliográficas}

ANTUNES, A.; TATIT, P.; RUIZ, A. BANDEIRA, J. Se tudo pode acontecer. In: ANTUNES, A. Paradeiro. São Paulo: BMG, 2001. CD-ROM.

BARROCO, M. L. Ética e serviço social: fundamentos ontológicos. São Paulo: Cortez, 2001.

CFESS. Código de ética do assistente social e lei 8.662/93. 3ª ed. rev. e atualiz. Brasília: CFESS, 1997.

. Projeto da campanha pela liberdade de orientação e expressão sexual. Brasília: CFESS, 2006 ${ }^{\text {a }}$. Disponível em: <http:www.cfess.org.br>. Acesso em 28 ago. 2006.

. Resolução CFESS n. 489, de 03 de junho de 2006. Estabelece normas vedando condutas discriminatórias ou preconceituosas, por orientação e expressão sexual por pessoas do mesmo sexo, no exercício profissional do assistente social, regulamentando princípio inscrito no Código de Ética Profissional. Brasília: CFESS, 2006b. Disponível em: <http://www.cfess.org.br/pdf/resolucao_4892006.pdf>. Acesso em 9 out.2011. _. CFESS Manisfesta: análises conjunturais. Brasília: CFESS, 2008 Disponível em: <http://www.cfess.org.br/arquivos/CFESSMANIFESTA 2005-2008.pdf>. Acesso em 09 out. 2011.

. Relatório final de gestão: Atitude crítica para avançar na luta (2008-2011). Brasília: CFESS, 2011a. Disponível em: <http://www.cfess.org.br/arquivos/ RELATORIO_GESTAO_2008-2011.pdf>. Acesso em 09 out. 2011.

. Liberdade de orientação sexual e não à homofobia. In: CFESS Manifesta: dia internacional do orgulho LGBT. Brasília: CFESS, 28 jun. 2010a. Disponível em: $<$ http://www.cfess.org.br/arquivos/cfessmanifesta_diaorgulholgbt_APROVADO.pdf>. Acesso em 09 out. 2011.

. O amor exige expressão e reverência coletiva. In: CFESS Manifesta: dia nacional da visibilidade lésbica. Brasília: CFESS, 29 ago. 2010b. Disponível em: <http:/ /www.cfess.org.br/arquivos/cfess_manifesta_visibilidadelesbicaFINAL.pdf>. Acesso em 09 out. 2011.

. Gestão atitude crítica para avançar na luta (2008-2011). In: CFESS Manifesta. Brasília: CFESS, 2011b. Disponível em: <http://www.cfess.org.br/publicacoes_li vros.php>. Acesso em 09 out.2011.

Relatório final: $40^{\circ}$ encontro nacional do conjunto CFESS-CRESS. CFESS: Brasília, 2011c. Disponível em: <http://www.cfess.org.br/arquivos/relatoriofinal_ 40NACIONAL.pdf>. Acesso em 09 out.2001.

. Resolução CFESS n. 615, de 08 de setembro de 2011. Dispõe sobre a inclusão e uso do nome social da assistente social travesti e do(a) assistente social transexual nos documentos de identidade profissional. Brasília, 2011d. Disponível em <http:/ /www.cfess.org.br/arquivos/615-11.pdf>. Acesso em 09 out. 2001.

HELLER, Agnes. O cotidiano e a história. Rio de Janeiro: Paz e Terra, 1989. 
heVigtg QIII Pgutd

\} "O AMOR FALA TODAS AS LÍNGUAS" - MESQUITA, M. \& MATOS, M. C. \}

HOLLANDA, C.B. Apesar de você. Phillips/Polygram, 1978, long-play. [1970, disco compacto]. Disponível em <http://www.chicobuarque.com.br/discos/mestre.asp?.pg= chico_78.htm>. Acesso em 01 mar. 2012.

MARX, K. Crítica do programa de Gotha. In: MARX, K. \& ENGELS, F. Obras escolhidas. São Paulo: Alfa e Ômega, 1980.

MESQUITA, M. Assistente social na luta contra o preconceito: campanha pela liberdade expressão e orientação sexual. In: Anais "Conferências e Deliberações do 35" Encontro Nacional CFESS/CRESS". Brasília: CFESS, 2009.

. Orientação sexual: experiência privada, opressão privada e pública - Um desafio para os direitos humanos. In: ABEPSS, CFESS, ENESSO, CRESS 7a região. $10^{\circ}$ Congresso Brasileiro de Assistentes Sociais (CBAS): "Trabalho, Direitos e Democracia: assistentes sociais contra a desigualdade", UERJ, 2001. CD-ROM.

. Heterossexualidade compulsória e homofobia/lesbofobia/transfobia: elementos conceituais para compreensão crítica da violação de direitos da população LGBT. In: SANTOS, S.M.M. et al (Org.). Pensamento crítico e diversidade humana. Natal: EDUFRN (no prelo).

MESQUITA, M.; SANTOS, S.M.M.; RAMOS, S.. Contribuições à crítica do preconceito no debate do Serviço Social. Revista Presença Ética. Recife: UNIPRESS Gráfica e Editora do NE Ltda., no 01, 2001, p. 67-89.

PECHENY, M. Identidades discretas. In: RIOS, L.F. et al (Orgs.). Homossexualidade: produção cultural, cidadania e saúde. Rio de Janeiro: Abia, 2004.

PRINCÍPIOS DE YOGYAKARTA. Princípios sobre a aplicação da legislação internacional de direitos humanos em relação à orientação sexual e identidade de genero. Disponível em: <http://www.clam.org.br/pdf/principios_de_yogyakarta.pdf>. Acesso em 11 out. 2011.

SANTOS, S.M.M. Assistente Social na luta contra o preconceito: campanha pela liberdade expressão e orientação sexual. In: Anais: conferências e deliberações do 35º encontro nacional CFESS/CRESS. Brasília: CFESS, 2009.

- O CFESS na defesa das condições de trabalho e do projeto ético-político profissional. Revista Serviço Social e Sociedade. São Paulo: Cortez, n. 104, out. 2010, p. 695-714.

Recebido em 23 de setembro de 2011

Aceito para publicação em 15 de dezembro de 2011 